\title{
Cholesteryl derivatives with a sulfonyl moiety
}

\author{
Carmen Topală, Miron T. Căproiu, ${ }^{a}{ }^{b}$ and Constantin Drăghici \\ University of Piteşti, Departament of Chemistry, Tg. Vale, Nr. 1, Piteşti 03000, Romania \\ Institute of Organic Chemistry, NMR Department, Spl. Independentei 202B, Bucharest \\ 15 PO Box 258, Romania
}

E-mail: $\underline{\text { mtc@eco.ro }}$

\section{Dedicated to Professor Alexandru T. Balaban on his $75^{\text {th }}$ birthday}

(received 19 Oct 04; accepted 27 Jan 05; published on the web 04 Mar 05)

\begin{abstract}
Cholesteryl carbamates were prepared by reactions of cholesterylchloroformate with phenylsulfonylanilines, in the presence of pyridine as acid acceptor. Two other cholesteryl carbonates with a heterocyclic moiety were prepared in order to evaluate the effect of variation of the terminal group on the substituted cholesteryl system. The thermodynamic properties of cholesteryl derivatives were characterized by DSC and the texture of the mesophases have been determined with a hot stage equipped polarizing microscope. The relative thermal stabilities and the variation on the mesomorphic characteristics also have been studied.
\end{abstract}

Keywords: Diphenylsulfonyl, cholesteryl carbamates, mesogen, transition temperature

\section{Introduction}

Steryl esters, particularly cholesteryl esters are used for technical applications such as liquid crystals. Lehn and Ringsdorf have explored the use of this concept in a number of areas: photochemical control of phase changes, optical memory devices, "one-dimensional" conductors and photoconductors. 1,2 Various compounds have been reported with liquid crystalline properties, but cholesteryl esters with sulfonyl and heterocyclic sulfonyl moieties have been explored to a much lesser extent. ${ }^{3,4}$

We have recently described the synthesis of phenoxy-cholesteryl and thiophenoxycholesteryl carbamates, compounds with liquid crystalline properties. ${ }^{5,6} \mathrm{We}$ have endeavored to extend this area by the synthesis of new steroid carbamates with a sulfonyl moiety, compounds 5-8 (Figure 1). In the present study we also have investigated the mesomorphic characteristics of several structurally related cholesteryl derivatives with a sulfonyl moiety, compounds 1-10 
(Figures 1 and 2) in which the nature of terminal moiety is changed. Moreover, an attempt has been made to link the changes observed in mesophase thermal stability to the changes in moiety.

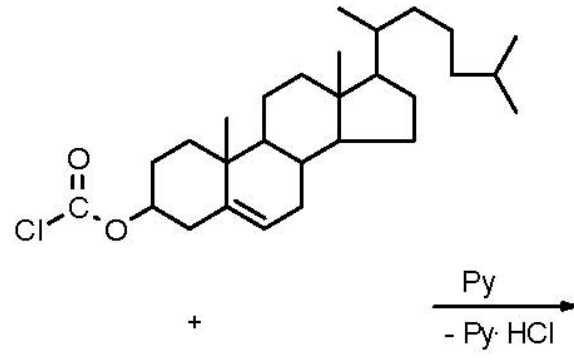

$\longrightarrow-\mathrm{N}-\mathrm{NH}_{2}$

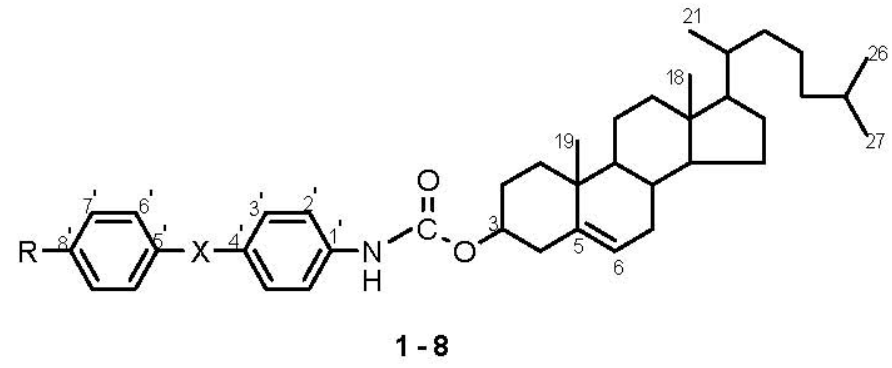

1: $\mathrm{R}=\mathrm{Cl}, \mathrm{X}=\mathrm{S}, 2: \mathrm{R}=\mathrm{Br}, \mathrm{X}=\mathrm{S} ; 3: \mathrm{R}=\mathrm{CH}_{3}, \mathrm{X}=\mathrm{S} ; 4: \mathrm{R}=\mathrm{NO}_{2} \mathrm{X}=\mathrm{S}$

5: $\mathrm{R}=\mathrm{Cl}, \mathrm{X}=\mathrm{SO}_{2} ; 6: \mathrm{R}=\mathrm{Br}, \mathrm{X}=\mathrm{SO}_{2} ; 7: \mathrm{R}=\mathrm{CH}_{3}, \mathrm{X}=\mathrm{SO}_{2} ; 8: \mathrm{R}=\mathrm{NO}_{2}, \mathrm{X}=\mathrm{SO}_{2}$

Figure 1

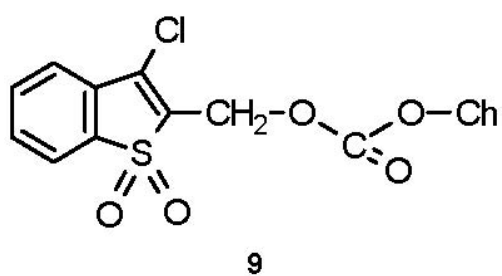

9

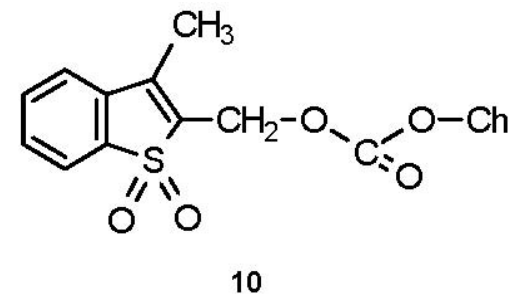

10

where Ch: rest of cholesteryl

Figure 2

\section{Results and Discussion}

Syntheses of cholesteryl carbamates $\mathbf{5}-\mathbf{8}$ were performed in dry benzene (pyridine was used as acid acceptor) and all reactions were monitored by thin-layer chromatography (TLC). The products obtained in the usual manner were purified by column chromatography and thereafter crystallized.

The recrystallization of new carbamates from methyl ethyl ketone and ethanol led to high purity compounds. Selective reflection of these carbamates in the visible region was observed in solvents such as: amyl alcohol, mixtures ethanol-benzene, and methyl ethyl ketone. The selective reflection, as well as the optical activity, remarkably influence the optical appearance (textures) of cholesteric phases.

The common structural features of compounds 1-8 consist of two phenyl rings and a cholesteryl skeleton linked through $\mathrm{S}$ or $\mathrm{SO}_{2}$ and carbamate central linkages, with different 
terminal groups at one end. Compounds $\mathbf{9}$ and $\mathbf{1 0}$ also contain a sulfonyl group in a heterocyclic structural linkage to the cholesteryl framework.

\section{IR and NMR data for compounds 5 - 8}

The newly synthesized cholesteryl carbamates with a diphenylsulfonyl moiety were characterized using IR and NMR spectra. Table 1 shows the IR values obtained in $\mathrm{CCl}_{4}$ for compounds 5-8.

In the IR spectra, the most prominent vibrations observed for all the compounds were the carbonyl group vibration at $1708-1736 \mathrm{~cm}^{-1}$ (strong), $1210-1216 \mathrm{~cm}^{-1}$ (very strong) for C-O and $3410-3440 \mathrm{~cm}^{-1}$ (strong) for NH. Vibrations at 2930-2970 $\mathrm{cm}^{-1}$ and $2866-2875 \mathrm{~cm}^{-1}$ characterized the methyl groups from the steroid nucleus.

In the ${ }^{1} \mathrm{H}-\mathrm{NMR}$ spectra, the cholesteryl nucleus presented a multiplet at $0.90-2.10 \mathrm{ppm}$ for the saturated portion. The methyl groups $\left(\mathrm{CH}_{3}-18\right.$ and $\left.\mathrm{CH}_{3}-19\right)$ appeared at $0.66-0.68$ ppm and $0.89 \mathrm{ppm}$, respectively, as singlets. The methyls at the 26 and 27 positions appeared as doublets at 0.86 and $0.87 \mathrm{ppm}$, with $6.6-6.8 \mathrm{~Hz}$ coupling constants. The 21 methyl was a doublet at 0.90 ppm with a $6.5-6.7 \mathrm{~Hz}$ coupling constant. Additionally, the $3 \alpha-\mathrm{H}$ appeared in all compounds as a multiplet at 4.58-5.12 ppm.

In the ${ }^{13} \mathrm{C}$-NMR spectra, discrimination of carbon atoms, the order of substitution, respectively, was carried out by the Attached Proton Test (APT). The rest of the sterolic skeleton presented characteristic shifts for 27 atoms and they were identical with literature values. ${ }^{7}$ It was possible to distinguish the $\mathrm{C}-3$ geminal with oxygen at $75.65-75.78 \mathrm{ppm}$.

Table 1. IR values $\left(\mathrm{cm}^{-1}\right)$ for compounds $5-8$

\begin{tabular}{ccccc}
\hline Compounds & $\mathbf{v}_{\mathrm{C}=\mathrm{O}}$ & $\mathbf{v}_{\mathrm{C}-\mathrm{O}(\operatorname{sim})}$ & $\mathbf{v}_{\mathrm{C}-\mathrm{O}(\operatorname{asim})}$ & $\mathbf{v}_{\mathrm{N}-\mathrm{H}}$ \\
\hline $\mathbf{5}$ & 1708 & 1216 & 1052 & 3410 \\
$\mathbf{6}$ & 1720 & 1210 & 1052 & 3440 \\
$\mathbf{7}$ & 1736 & 1211 & 1049 & 3416 \\
$\mathbf{8}$ & 1730 & 1210 & 1050 & 3420 \\
\hline
\end{tabular}

\section{Thermal behaviour}

In order to realize a complete physicochemical characterization for the synthesized carbamates, a thermodynamic study of thermal transition characteristics was necessary. The transition path and thermodynamic function were measured by differential scanning calorimetry (DSC) and Böetius thermomicroscopy (TM).

The first investigation was carried out by Böetius thermomicroscopy. For each compound, the kind of mesophases and their modifications at various temperatures were studied (form of crystals, colour etc.). This determination, though very suggestive, does not confer a high precision in establishing the transition temperature and in our conditions it could not be done under an inert environment. 
From DSC curves, thermodynamic transition functions $\Delta^{t r} H, \Delta^{t r} S$ could be calculated exactly using the relations:

$$
\begin{aligned}
& \Delta^{t r} H=\frac{k \cdot A \cdot R}{s \cdot w} \quad\left(\operatorname{calg}^{-1}\right)(1) \\
& \Delta^{t r} S=\frac{\Delta^{t r} H}{T_{t r}} \quad\left(\operatorname{calg}^{-1} K^{-1}\right)(2) \\
& k \text { - instrument constant } \\
& A \text { - peak area }\left(\mathrm{mm}^{2}\right) \\
& s \text { - unrolling speed of recorder paper }\left(\mathrm{mm} \mathrm{min}^{-1}\right) \\
& w \text { - the sample weight (mg) } \\
& R \text { - the apparatus sensitivity (mcal s }{ }^{-1} \text { ) } \quad T_{t r} \text { - transition temperature (K) }
\end{aligned}
$$

From these thermodynamic functions, the variation of thermodynamic Gibbs potential could be estimated. ${ }^{8}$

The transition temperatures and associated enthalpies for compounds 1-10 are summarized in Table 2 .

The thermodynamic stability of a liquid crystalline phase can be characterized in terms of a clearing point $\left(T_{N I}\right)$, the temperature at which the energy contents of the anisotropic and isotropic liquids are equal, and these points are presented in table 2 , as the second value. The first value of temperature in table 2 is the melting point as transition temperature.

It is resonable to assume that the presence of a phenylsulfonyl unit increases both the length of the lateral chain at C-3 of the molecules and the clearing points. Consequently, a more polar wing group to a rigid structure would probably be necessary in these compounds to obtain a mesophase.

The compounds with $-\mathrm{CH}_{3}\left(3,7\right.$ and 10), $-\mathrm{NO}_{2}(4$ and 8), $-\mathrm{Cl}(\mathbf{1}, 5$ and 9), $-\mathrm{Br}(2$ and 6$)$ end groups exhibit liquid crystal phases, with the mesophase range being least for the compound having a $-\mathrm{CH}_{3}$ group at the terminal position. The mesophase range is maximal when the $-\mathrm{CH}_{3}$ group is replaced by the $\mathrm{NO}_{2}$ moiety. A methyl group is mildly polar, while a nitro group will endow the molecules with high polarity, greater terminal attraction and, hence, a higher mesophase range. ${ }^{9}$ Bromo and chloro groups also effect polarity, but as the bromo moiety is somewhat larger than the chloro, this explains the lower phase range of the bromo compound. The group efficiency order for phase thermal stability can be derived for the compounds as follows:

$$
-\mathrm{NO}_{2}>-\mathrm{Br}>-\mathrm{Cl}>-\mathrm{CH}_{3}
$$

This agrees well with the group efficiency order obtained by Gray for pure mesogenic systems. $^{10}$ 
Table 2. Enthalpies, entropies and transition temperatures established by DSC and TM* measurements

\begin{tabular}{|c|c|c|c|c|c|}
\hline Compound & $\begin{array}{c}\text { Linkage } \\
-\mathrm{X}-\end{array}$ & Terminal group $-R$ & $T_{\text {tr }}\left({ }^{\circ} \mathrm{C}\right)$ & $\Delta{ }^{\mathrm{tr}} \mathrm{H}(\boldsymbol{k} C \mathrm{Cal} / \mathrm{mol})$ & $\Delta^{\mathrm{tr}} \mathrm{S}(\boldsymbol{k} C \mathrm{al} / \mathrm{mol} \cdot \mathrm{K})$ \\
\hline 1 & $\mathrm{~S}$ & $\mathrm{Cl}$ & $\begin{array}{l}144.27 \\
161.34\end{array}$ & $\begin{array}{l}8.37 \\
0.24\end{array}$ & $\begin{array}{l}2.01 \cdot 10^{-2} \\
5.52 \cdot 10^{-4}\end{array}$ \\
\hline 2 & S & $\mathrm{Br}$ & $\begin{array}{c}150^{*} \\
156.59\end{array}$ & 0.24 & $5.58 \cdot 10^{-4}$ \\
\hline 3 & $\mathrm{~S}$ & $\mathrm{CH}_{3}$ & $\begin{array}{l}130.59 \\
134,01\end{array}$ & $\begin{array}{c}11,94 \\
0,25\end{array}$ & $\begin{array}{l}2.95 \cdot 10^{-2} \\
6.14 \cdot 10^{-4}\end{array}$ \\
\hline 4 & $\mathrm{~S}$ & $\mathrm{NO}_{2}$ & $\begin{array}{l}221.10 \\
257.09\end{array}$ & $\begin{array}{l}8.37 \\
0.24\end{array}$ & $\begin{array}{l}1.69 \cdot 10^{-3} \\
4.53 \cdot 10^{-4}\end{array}$ \\
\hline 5 & $\mathrm{SO}_{2}$ & $\mathrm{Cl}$ & $\begin{array}{l}229.84 \\
235.59\end{array}$ & 1.80 & $3.56 \cdot 10^{-3}$ \\
\hline 6 & $\mathrm{SO}_{2}$ & $\mathrm{Br}$ & $\begin{array}{l}246.54 \\
250.84\end{array}$ & 1.90 & $3.56 \cdot 10^{-3}$ \\
\hline 7 & $\mathrm{SO}_{2}$ & $\mathrm{CH}_{3}$ & $\begin{array}{l}239.84 \\
242.09\end{array}$ & $\begin{array}{l}2.10 \\
0,42\end{array}$ & $\begin{array}{l}4.09 \cdot 10^{-3} \\
8.15 \cdot 10^{-4}\end{array}$ \\
\hline 8 & $\mathrm{SO}_{2}$ & $\mathrm{NO}_{2}$ & $\begin{array}{c}250^{*} \\
274.10\end{array}$ & 0.45 & $8.22 \cdot 10^{-4}$ \\
\hline 9 & & $\mathrm{Cl}$ & $\begin{array}{l}115.84 \\
128.34\end{array}$ & 4.38 & $1.12 \cdot 10^{-2}$ \\
\hline 10 & & $\mathrm{CH}_{3}$ & $\begin{array}{l}165.90 \\
168.84\end{array}$ & 6.91 & $1.57 \cdot 10^{-2}$ \\
\hline
\end{tabular}

\section{Conclusions}

Four new cholesterylcarbamates $(5$ - 8) with a phenylsulfonyl moiety, which exhibit liquid crystals properties, were synthesized. Mesomorphic characteristics were studied for ten cholesteryl derivatives in which the nature of the terminal group was changed. It was observed, by varying the polarizability of the $R$-terminal group, that polarity contributed to the changes observed in transitions, mesophase temperature range and mesophase textures. The melting points and clearing points appeared to be influenced mainly by the organic moiety. 


\section{Experimental Section}

General Procedures. Cholesteryl carbamates $\mathbf{1}-\mathbf{4}$ and carbonates 9 and $\mathbf{1 0}$ were obtained in pure state by reported methods. ${ }^{5,11}$ New cholesteryl derivatives, compounds $\mathbf{5}-\mathbf{8}$, were obtained by condensation of cholesterylchloroformate with 4-substituted benzenesulfonylanilines in anhydrous benzene, in the presence of pyridine. Cholesteryl chloroformate was an Aldrich product. Phenylsulfonylanilines were preparated from phenylsulfanylanilines after protection of the amino group and then oxidation with acetic acid and peroxide.

Pure crystals of the desired cholesterylcarbamates were obtained by recrystallization from a mixture methyl ethyl ketone and ethanol.

The purity of all compounds was checked by thin layer chromatography (Merck Kieselgel $60 \mathrm{~F}_{254}$ pre-coated plates) and the chemical structures of these were confirmed by ${ }^{1} \mathrm{H}-\mathrm{NMR},{ }^{13} \mathrm{C}-\mathrm{NMR}$ and IR spectroscopy.

The IR spectra were recorded with an UR 20 Carl-Zeiss Jena spectrophotometer.

The ${ }^{1} \mathrm{H}-\mathrm{NMR}$ and ${ }^{13} \mathrm{C}-\mathrm{NMR}$ spectra were performed on a Varian Gemini $300-\mathrm{BB}$ instrument. All the NMR spectra were recorded at ambient temperature (ca. $295^{\circ} \mathrm{K}$ ) using deuterochloroform as solvent and TMS as internal standard; for ${ }^{13} \mathrm{C}-\mathrm{NMR}$ spectra the resonance line of deuterochloroform at $77.00 \mathrm{ppm}$ was taken as reference line.

The ${ }^{13} \mathrm{C}$-NMR spectra were run in quantitative conditions: pw (45), $20 \mathrm{~s}$ delay between pulses, the acquisition of $0.8 \mathrm{~s}$, the decoupler switch only in acquisition period and 2048 transients for each FID. Besides, NOE, COSY $\left({ }^{1} \mathrm{H}-{ }^{1} \mathrm{H}\right)$, COSY $\left({ }^{1} \mathrm{H}-{ }^{13} \mathrm{C}\right)$ and long range $\operatorname{COSY}\left({ }^{1} \mathrm{H}-{ }^{13} \mathrm{C}\right)$ pulse sequences were used for proton and carbon chemical shifts assignments.

The elemental analyses of all compounds corresponded with the calculated values.

The calorimetric measurements were made with a Perkin Elmer DSC 2 calorimeter in a highly purified argon atmosphere. The temperature was calibrated with the melting point of an indium standard. The weight of samples lay in the range of $3-5 \mathrm{mg}$. Typically heating and cooling rates of $10^{\circ} \mathrm{C} / \mathrm{min}$ were used. The peak temperatures of exo- and endotherms were used as the values of transitions.

For optical microscopy, thin films $(5-10 \mathrm{~m} \mu)$ were melted and pressed between the cover slips in a hot stage. A polarizing optical microscope equipped with a hot stage was used to observe morphological changes.

\section{Syntheses of cholesterylcarbamates 5-8. General procedure}

The amino compound $(5 \mathrm{mmol})$ and $0.5 \mathrm{~mL}$ of pyridine were dissolved in $40 \mathrm{~mL}$ of dry benzene. $5 \mathrm{Mmol}$ of cholesterylchloroformate in $40 \mathrm{~mL}$ of dry benzene was added dropwise during 20-30 minutes, with stirring. Stirring was continued and the reaction was monitored by thin-layer chromatography. When the reaction was complete, the benzene solution was washed with cold dilute hydrochloric acid and water, and dried over anhydrous sodium sulfate. Benzene was evaporated and the crude product purified by column chromatography and crystallized from a mixtured of methyl ethyl ketone and ethanol. Compounds $\mathbf{5}-\mathbf{8}$ were obtained in pure state. 
[4-(4-Chlorobenzenesulfonyl)phenyl]cholesterylcarbamate (5). The title compound was obtained in $80 \%$ yield as white plate crystals; $\mathrm{R}_{\mathrm{f}}=0.30$ (petroleum ether / ethyl ether 9:1); ${ }^{1} \mathrm{H}$ NMR $\left(\mathrm{CDCl}_{3}\right): 7.84$ (d, 2H, H-7', $\left.J=8.9\right), 7.75$ (d, 2H, H-6', $\left.J=8.9\right), 7.60$ (d, 2H, H-3', $J=$ 8.6), 7.50 (d, 2H, H-2', J=8.6), 6.85 (s, 1H, NH), 5.40 (m, H-6), 4.58 (m, H-3), 2.32 (m, 2H, H7), 2.39-0.87 (m, 26H), 1.02 (s, 3H, $\left.\mathrm{CH}_{3}-19\right), 0.91$ (d, 3H, $\left.\mathrm{CH}_{3}-21,6.6\right), 0.87$ (d, 3H, $\mathrm{CH}_{3}-26$ or $\left.\mathrm{CH}_{3}-27,6.6\right), 0.86$ (d, 3H, $\mathrm{CH}_{3}-27$ or $\left.\mathrm{CH}_{3}-26\right), 0.68$ (s, 3H, $\left.\mathrm{CH}_{3}-18\right)$; ${ }^{13} \mathrm{C}-\mathrm{NMR}\left(\mathrm{CDCl}_{3}\right): 152.40$ $(\mathrm{C}=\mathrm{O}), 143\left(\mathrm{C}_{\mathrm{q}}\right), 142.00\left(\mathrm{C}_{\mathrm{q}}\right), 139(\mathrm{C}-5), 134.80\left(\mathrm{C}_{\mathrm{q}}\right), 132.58(\mathrm{CH}), 129.20(\mathrm{CH}), 129.00(\mathrm{CH})$, $128.45\left(\mathrm{C}_{\mathrm{q}}\right), 123.09(\mathrm{C}-6), 118.92(\mathrm{CH}), 75.78(\mathrm{C}-3)$ and for the rest of cholesteryl framework the chemical shifts are similar to literature values; ${ }^{7}$ Elemental Anal. Calcd for $\mathrm{C}_{40} \mathrm{H}_{54} \mathrm{ClNO}_{4} \mathrm{~S}$ : C, 70.61; H, 7.99; N, 2.06. Found: C, 70.51; H, 8.04; N, $2.09 \%$.

[4-(4-Bromobenzenesulfonyl)phenyl]cholesterylcarbamate (6). The title compound was obtained in $89 \%$ yield as white plate crystals; $\mathrm{R}_{\mathrm{f}}=0.29$ (petroleum ether/ethyl ether 9:1); ${ }^{1} \mathrm{H}$ NMR $\left(\mathrm{CDCl}_{3}\right): 7.85$ (d, 2H, H-7', $\left.J=8.9\right), 7.77$ (d, 2H, H-6', J= 8.9), 7.62 (d, 2H, H-3', $J=$ 8.6), 7.52 (d, 2H, H-2', J=8.6), 6.87 (s, 1H, NH), 5.39 (m, H-6), 4.58 (m, H-3), 2.32 (m, 2H, H7), 2.39-0.87 (m, 26H), 1.03 (s, 3H, $\left.\mathrm{CH}_{3}-19\right), 0.91$ (d, 3H, $\left.\mathrm{CH}_{3}-21,6.6\right), 0.87$ (d, $\mathrm{CH}_{3}-26$ or $\mathrm{CH}_{3}-$ 27, 6.6), 0.86 (d, 3H, $\mathrm{CH}_{3}-27$ or $\left.\mathrm{CH}_{3}-26\right), 0.68$ (s, 3H, $\left.\mathrm{CH}_{3}-18\right)$; ${ }^{13} \mathrm{C}-\mathrm{NMR}\left(\mathrm{CDCl}_{3}\right): 152.38$ $(\mathrm{C}=\mathrm{O}), 142.99\left(\mathrm{C}_{\mathrm{q}}\right), 141.08\left(\mathrm{C}_{\mathrm{q}}\right), 139.22(\mathrm{C}-5), 134.61\left(\mathrm{C}_{\mathrm{q}}\right), 132.53(\mathrm{CH}), 129.16(\mathrm{CH}), 128.93$ $(\mathrm{CH}), 128.40\left(\mathrm{C}_{\mathrm{q}}\right), 123.07(\mathrm{C}-6), 118,90(\mathrm{CH}), 75,75(\mathrm{C}-3)$ and for the rest of cholesteryl framework the chemical shifts are similar to literature values; ${ }^{7}$ Elemental Anal. Calcd for $\mathrm{C}_{40} \mathrm{H}_{54} \mathrm{BrNO}_{4} \mathrm{~S}: \mathrm{C}, 66.28 ; \mathrm{H}, 7.51 ; \mathrm{N}, 1.94$. Found: C, 66.30; H, 7.45; N, 1.85\%.

[4-(4-Methylbenzenesulfonyl)phenyl]cholesterylcarbamate (7). The title compound was obtained in $85 \%$ yield as white plate crystals; $\mathrm{R}_{\mathrm{f}}=0.19$ (petroleum ether/ethyl ether 9:1); ${ }^{1} \mathrm{H}-$ NMR $\left(\mathrm{CDCl}_{3}\right)$ : 7.85-7.79 (m, 4H), 7.50 (d, 2H, H-7', $\left.J=8.9\right), 7.28$ (d, 2H, H-3', J= 8.5), 6.77 (s, 1H, NH), 5.39 (m, H-6), 4.60 (m, H-3), 2.39 (s, 3H, $\mathrm{CH}_{3}-8^{\prime}$ ), 2.39-0.87 (m, 28H), 1.02 (s, 3H, $\left.\mathrm{CH}_{3}-19\right), 0.91$ (d, 3H, $\left.\mathrm{CH}_{3}-21, J=6.6\right), 0.87$ (d, 3H, $\mathrm{CH}_{3}-26$ or $\left.\mathrm{CH}_{3}-27, J=6.6\right), 0.86(\mathrm{~d}, 3 \mathrm{H}$, $\mathrm{CH}_{3}-27$ or $\left.\mathrm{CH}_{3}-26\right), 0.68\left(\mathrm{~s}, 3 \mathrm{H}, \mathrm{CH}_{3}-18\right),{ }^{13} \mathrm{C}-\mathrm{NMR}\left(\mathrm{CDCl}_{3}\right)$ : $152.39(\mathrm{C}=\mathrm{O}), 142.98\left(\mathrm{C}_{\mathrm{q}}\right)$, $142.48(\mathrm{CH}), 139.26(\mathrm{C}-5), 139.05(\mathrm{CH}), 129.84\left(\mathrm{C}_{\mathrm{q}}\right), 128.00\left(\mathrm{C}_{\mathrm{q}}\right), 127.45\left(\mathrm{C}_{\mathrm{q}}\right), 123.03(\mathrm{C}-6)$, $118,11\left(\mathrm{C}_{\mathrm{q}}\right), 75,65(\mathrm{C}-3)$ and for the rest of cholesteryl framework the chemical shifts are similar to literature values; ${ }^{7}$ Elemental Anal. Calcd for $\mathrm{C}_{41} \mathrm{H}_{57} \mathrm{BrNO}_{4} \mathrm{~S}: \mathrm{C}, 74.62 ; \mathrm{H}, 8.70 ; \mathrm{N}, 2.12$. Found: C, 74.38; H, 8.47; N, 2.15\%.

[4-(4-Nitrobenzenesulfonyl)phenyl]cholesterylcarbamate (8). The title compound was obtained in $76 \%$ yield as white-beige needle crystals; $\mathrm{R}_{\mathrm{f}}=0.19$ (petroleum ether/ethyl ether 9:1); ${ }^{1} \mathrm{H}-\mathrm{NMR}\left(\mathrm{CDCl}_{3}\right): 7.20$ (d, 2H, H-7', $\left.J=7.9\right), 7.32$ (d, 2H, H-6', $\left.J=7.9\right), 7.35$ (d, 2H, H-3', $J=$ 8.6), 7.29 (d, 2H, H-2', J=8.6), 6.60 (s, 1H, NH), 5.35 (m, H-6), 4.56 (m, H-3), 2.32 ( m, 2H, H7), 2.39-0.87 (m, 26H), 1.03 (s, 3H, $\left.\mathrm{CH}_{3}-19\right), 0.91$ (d, 3H, $\left.\mathrm{CH}_{3}-21,6.6\right), 0.87$ (d, $\mathrm{CH}_{3}-26$ or $\mathrm{CH}_{3}-$ 27, 6.6), 0.86 (d, $3 \mathrm{H}, \mathrm{CH}_{3}-27$ or $\left.\mathrm{CH}_{3}-26\right), 0.68$ (s, 3H, $\left.\mathrm{CH}_{3}-18\right) ;{ }^{13} \mathrm{C}-\mathrm{NMR}\left(\mathrm{CDCl}_{3}\right): 152.60$ $(\mathrm{C}=\mathrm{O}), 142.96\left(\mathrm{C}_{\mathrm{q}}\right), 141.04\left(\mathrm{C}_{\mathrm{q}}\right), 139.45(\mathrm{C}-5), 134.60\left(\mathrm{C}_{\mathrm{q}}\right), 132.47(\mathrm{CH}), 129.10(\mathrm{CH}), 128.90$ $(\mathrm{CH}), 128.29\left(\mathrm{C}_{\mathrm{q}}\right), 122.80(\mathrm{C}-6), 118,90(\mathrm{CH}), 75,38(\mathrm{C}-3)$ and for the rest of cholesteryl framework the chemical shifts are similar to literature values; ${ }^{7}$ Elemental Anal. Calcd for $\mathrm{C}_{40} \mathrm{H}_{54} \mathrm{~N}_{2} \mathrm{O}_{6} \mathrm{~S}$ : C, 69.53; H, 7.88; N, 4.04. Found: C, 69.30; H, 8.20; N, 4.34\%. 


\section{Acknowledgements}

The authors gratefully acknowledge Prof. Viorica Meltzer for DSC analyses and useful comments.

\section{References}

1. Lehn, J. M. Angew. Chem. Int. Ed. 1990, 29, 1304.

2. Adam, D.; Schumacher, P.; Simmerr, J.; Hausling, L.; Siemensmeyer, K.; Etzbach, K. H.; Ringsdorf, H.; Haarer, D. Nature 1994, 371, 141.

3. Brown, J. W.; Hurst, D. T.; O’Donovan, J.P. Liq. Cryst. 1994, 17, 689.

4. Topală, C.; Ioniță, G.; Meltzer, V.; Pincu, E.; Drăghici C. Arkivoc 2002, (ii), 87.

5. Baciu, I.; Drăghici, C.; Topală, C.; Arsenescu, N. Rev. Roum. Chim. 2000, 45, 525.

6. Meltzer, V.; Topală, C.; Pincu, E. Rev. Roum. Chim. 2002, 47, 839.

7. Breitmaier, E.; Voelter, W. ${ }^{13}$ Carbon NMR Spectroscopy, $2^{\text {nd }}$ Edn; VCH: Weinheim, 1990; pp 272-293.

8. Vîlcu, R. Termodinamica Chimică, $2^{\text {nd }}$ Edn; Tehnică: Bucureşti, 1994; 120.

9. Gray, G. W.; Harrison, J. K. Mol. Cryst. Liq. Cryst. 1971, 13, 37.

10. Gray, G. W.; Winsor, P, A. Liquid Crystals and Plastic Crystals, Chichester: England Ellis Horwood Ltd, 1974; Vol 1, pp116-122.

11. Baciu, I.; Cîrlănaru-Topală, C.; Sferdean, C.; Drăghici, C.; Căproiu, M. T. Rev. Chimie (Bucureşti) 2001, 52, 14. 